\title{
PROPOSED BUSINESS MODEL OF A MICROLEARNING-BASED PLATFORM FOR CONTINUING PROFESSIONAL EDUCATION OF INDUSTRY MEMBERS
}

\author{
José Ricardo Mendes \\ dos Santos Gerbaudo \\ UFABC \\ Santo André, São Paulo, Brazil
}

\author{
Ricardo Gaspar \\ UFABC \\ Santo André, São Paulo, Brazil
}

\author{
Carla Marangoni De Bona \\ PUC-SP
}

São Paulo, São Paulo, Brazil

\author{
Nicolas Laur Oliveira \\ Camara Cesar \\ UFABC \\ Santo André, São Paulo, Brazil
}

\author{
Gabriel Florêncio Alves \\ SENAI/SP \\ São Paulo, São Paulo, Brazil
}

\begin{abstract}
The increasing mobility of people, objects and information resources opens up new perspectives for teaching and learning processes, especially for people who carry out their work while being mobile. This research proposes a business model innovation (BMI) in e-learning through a microlearning-based platform for continuing education of professionals. Microlearning is a type of learning based on micro content, that consists of fragmented multimedia content that provides quick responses to an idea envisioned in a previously well-delineated and purposeful scope. Such content may also be used to deal with broad and / or complex subjects by using chaining or sequencing techniques, so the fragments are grouped in a chronological fashion to create a broader idea on the topic being studied, and each fragment must be independent from each other. In addition, this content format has high power to hold the audience's attention and motivate the viewer's engagement. When people are looking for quick answers in video tutorials, they typically skip ahead at intervals of the video timeline until they find the stretch that contains the solution they need. For this reason, the format design of the videos consists of presenting the quick solution at the beginning, then a more detailed demonstration of the solution, accompanied by the theoretical conceptualization when necessary for its understanding. The proposed platform breaks the paradigm of the strongly structured and static teaching-learning process, bringing the possibility of dynamic and personalized reorganization of micro contents.
\end{abstract}

Keywords: learning, microlearning, professional education, vídeo lectures, mobile learning.

\section{INTRODUCTION}

With the increasing use of the Internet for educational purposes over the last years, several eLearning platforms have become sources of information to learners all over the world. Now, there is an increasing interest and need in evaluating the effectiveness of such learning processes spread across the web. This is of special interest to the industry, since its need for ever increasing quality of specialized workforce, and the coming challenges related to the development of a new production style based on intelligent processes, known as Industry 4.o. The connectivity brought by mobile devices with internet access influenced the means by which people look for new knowledge, even related to their carrier and personal development. Those devices have made finding information an easy and fast task, and that change affected how people learn and consume educational contents. Understanding the patterns of consumption of educational content offers an opportunity to increase the quality of training offered to manpower, thus cooperating with the development of the industry in Brazil.

This paper aims to present a business model of a microlearning-based educational platform, aligned with the educational content consumption profile of industry professionals. The main innovation aspect of this business model consists in how information is delivered to the platform user, in a microlearning fashion. Microlearning is a pedagogy centered around the concept of chunks of content which can be easily assimilated. It goes well with ever changing, velocity-based ways of information consumption, and has been seen as a promising strategy for delivering corporative training to employees. However, only few corporations are exploring this approach to professional education in Brazil, yet. In the next sections of this article, the foundations of a microlearning approach to eLearning are discussed, along with its relevance to the audience interested on learning through the internet. Based on this theoretical framework, and using a tool known as Business Model Canvas, it's offered a business model to the platform, centered around the demands of the audience. 


\section{FOUNDATIONS}

In the last two decades, mobile devices have become increasingly present in everyday life, and significant investments have been made to provide resources for the integration of these devices into educational contexts [1,2]. In addition, the eLearning market has grown dramatically in recent years [3], with promising growth estimates for the coming years. Despite the increasing demand for online educational content, institutions that offer this type of service suffer from high dropout rates in their courses [4]. Although the development of technology opens new possibilities in the pedagogical field, it has been argued that these devices have been used to reinforce traditional, one-size-fits-all, teacher-centered teaching practices [5]. In order to reduce high dropout rates in courses, not only do students need to adapt and develop new skills that online learning demands, but also instructors must revise traditional design and pedagogical approaches. With the rise of Generation $\mathrm{Z}$ as the main consumer segment, starting in 2020, in the online video market (representing around 40\% of consumers), pedagogical approaches need to consider what this generation values when searching content in the Internet. In a study carried out by SENAI [6], it was evidenced that the profile of video consumers, among professionals in the industry, values quality content (from the point of view of information, as well as design and oratory / charisma of the instructor), which can be easily accessible and that directly addresses the problem to be solved in the video, without deviating from this solution, unless to address a history of difficulties that the student may face when faced with the problem situation. Based on this scenario, we propose in this article a business model for an educational platform based on microlearning, which is a pedagogy adapted to the needs of the clients of this Market, focusing on the ease and speed of content absorption, addressing complex themes in the form of small segments (chunks) of information and content [7], which has been very promising, especially in the mobile learning environment, with the help of the rapid development of technologies related to mobile devices [8]. A business model describes the rationale of how an organization creates, delivers, and captures value, and the BMC (Business Model Canvas) is a tool for describing, analyzing and designing those models. In the next section of this article, it's described how the Canvas was elaborated.

\section{METHODOLOGY}

A business model is defined as a system that solves the problem of identifying who the consumers are, engaging with their needs, delivering satisfaction and monetizing value [14]. It is a description of how your company intends to create value in the market, and includes a unique combination of products, services, image and distribution that the company carries out. It also includes the subsequent organization of people and the operational infrastructure they use to carry out their work. [15] In a study carried out by Osterwalder [16], several business construction models were compared, aiming to identify the most mentioned in the literature. The components proposed by Ostenwalder and Pigneur (2011) [17] are: customer segment, value proposition, channels (communication, distribution and sales), customer relationships, revenue sources, key resources, key activities, key partnerships and cost structure. The detailed description of each of these components can be found in Table 1, below. Based on these components, the authors developed a tool to describe, visualize, evaluate and change business models, called Business Model Canvas, which can be visualized in Figure 1, below (adapted illustration).

The Figure is divided strategically into three macro topics of interest: Cost Structure: aspects of the business that cost money; Revenue Streams and Pricing Model: aspects that make money; and a mission.

\section{Mission}

The mission consists of what problem the business wants to solve, and how it intends to do so. It is the core of the business activities, stating a need for objectiveness and clarity to guide all the development of the business model.

\section{Cost Structure}

Over the Cost Structure, there are three key points that should be evaluated: Key Partners: who is needed to work with in order to be able to deliver the proposed solution; Key Activities: what is need to do to run the business; and the Key Resources which consists of what is a "must have" to run the activities of the business. All these questions should be summarized and thought in light of their costs.

\section{Revenue Streams and Pricing Model}

The key aspects that generate money to the business include the Customer Relations: how the business get more clients and stablishes communication with them; The Channels by which the solution is delivered to the clients; and the 
Market and Customers Segments which consists of an analysis of the needs of customers, how many people need the solution, and how many will need the solution eventually.

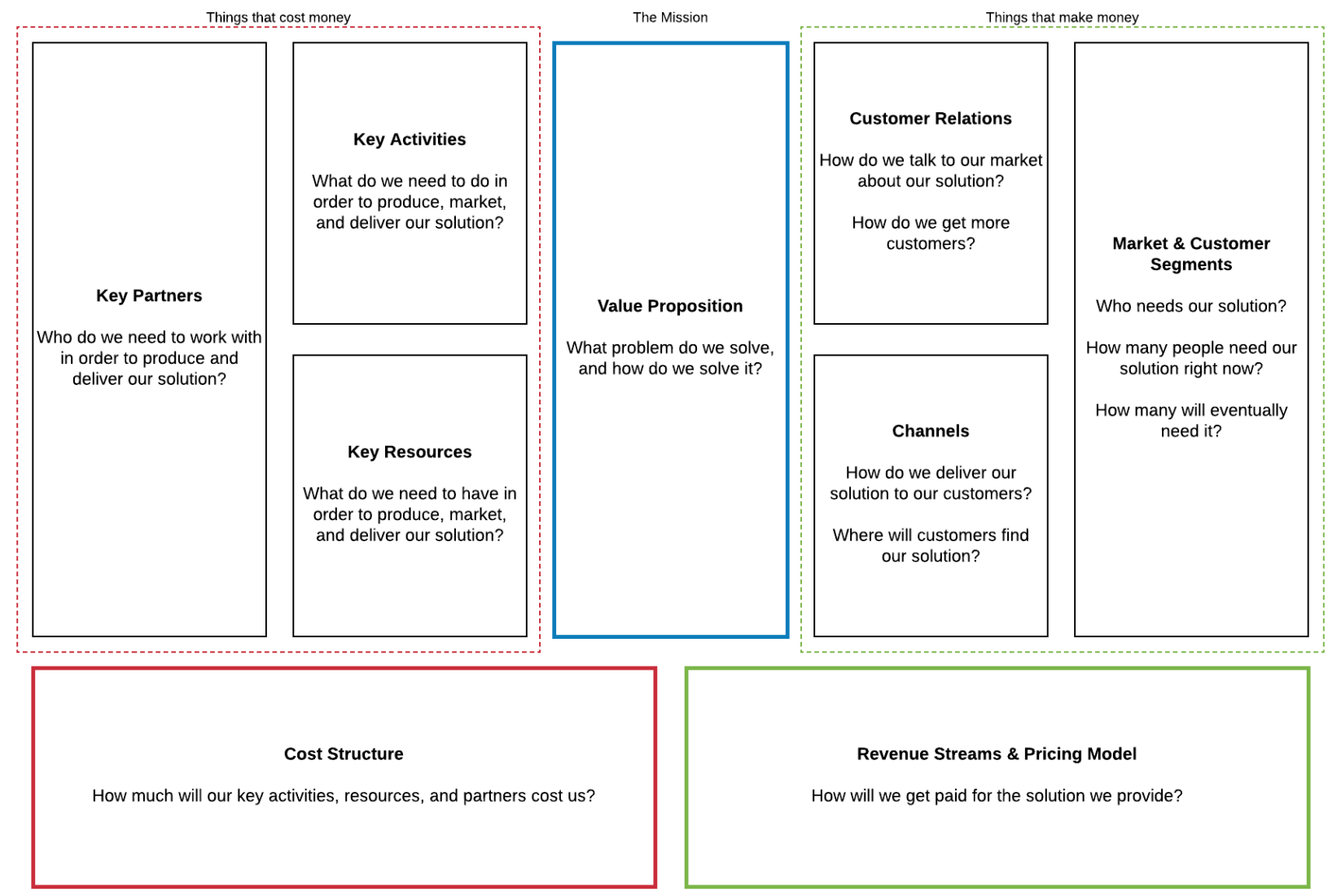

Figure 1. Ostenwalder and Pigneur's Business Model Canvas Components. The business canvas can be used to guide the elaboration of a business plan for a product, service, or company.

Based on this tool it was created the business model for the platform. In the elaboration process, the team from Escola SENAI de Informatica organized a series of meetings to discuss the nine main components of Osterwalder's BMC, and the findings will be discussed in the next section (Results).

\section{RESULTS}

Next, we present a frame (adapted from Macedo et al, 2013 [13]) that summarizes the answered basic questions which should guide the development of our proposed service, based on that business model canvas structure mentioned above. It is presented here segmented by Cost Structure, Revenue Streams, and Mission, to enhance the visualization of each topic.

Mission: What value do we deliver to the customer? What problem are we helping solve? What needs are we satisfying? What set of products and services are we offering for each customer segment?

Figure 2 shows the core objective of the microlearning-based platform we propose. The mission of the project is to deliver quality educational content, which could be easily accessed and assimilated, and that the industry workers could benefit from, in order to develop their professional skills. In this platform, the user can access its contents, be evaluated by his/her progress, and own certifications if approved. All aspects of Cost Structure and Revenue Streams are centered in this concept of business, which is aligned with the needs of the public consuming educational videos in the web which work in industry in Brazil, according to previous research conducted by SENAI, with results mentioned in the Foundations section of this article: they need content which is objective and goal-oriented (not deviating from the issue being discussed in the video) that praises for quality of information and oratory / charisma skills of the tutors, and can be easily accessed from anywhere, at any time. 


\section{Mission}

What problems do we solve? How do we solve it?

We deliver quality educational content that can be accessed from anywhere, and meet the needs for speed in the consumption of information to solve our customers' problems, while offering a continuing professional training to them. For this, we offer a digital elearning platform based on microlearning pedagogy, in which the user can access the contents, be evaluated and win certifications.

Figure 2. Mission of the proposed project.

Cost Structure: What are the most important costs in our business model? What major features are more expensive? Which key activities are more expensive?

Figure 3 below describes the three Key Factors concerning the Cost Structure. The Key Partners of our project, specifically, are other SENAI schools and member companies of the Industry. The schools could offer their expertise to the production of content, and the companies could afford costs of the project, e.g. in exchange of designing special qualifications in the area of actuation of the company, so we could deliver qualification to their manpower. Also, it is important to highlight the role of the suppliers in the partners section. In order to create the video contents for the platform, the main suppliers include distributors of audiovisual material (e.g cameras, computers, microphones and the like). The Key Activities consists of the production and curation of the educational content; the development of a website to allocate the platform, even UX as though Dev matters; and the monitoring and evaluation of students, and issuance of certificates for those willing to obtain professional certification from our institute. Other important activities are worthy highlighting, such as administrative and marketing routines. The Key Resources include an environment and team to create the audiovisual content aiming the mission of the project; Online platforms such as YouTube and its own website for allocate and distribute content; and a Marketing Team to run actions towards reaching the customers.

Figure 4 summarizes the components of the Revenues Streams and Pricing Models of the BMC. The Customer Relations states about the target public of the platform. In our case, we set the public as being professionals of the industry who seek professional or educational leverage. Based on the report published by SENAI [6], those professionals consist mainly in youngster and adults, aged 20-35. Thus, learners seeking acquiring new knowledge, or solving a specific problem of the areas/subjects covered by the platform may benefit from it as well. The main channels of distribution of content would be the platform itself, and the YouTube, since it is, today, the most accessed platform in terms of video content, even for educational purposes. In the end, it will be stablished a direct communication channel with the audience, as Customer Relationships politics, so they can send their feedback and suggestions, not only about the platform functionality or the content already provided but aiming to get new relevant content suggestions for creation, too. The business main source of resources is the support of SENAI itself, but partnerships with industry corporations and the issuance of certificates to those willing to get a certification of their knowledge by a traditional and recognized by the market institution also constitutes sources of revenue to the project. 
Key Partners

Who do we need to work with?

SENAI and member companies of the Industry; The main suppliers are producers of equipment for the production of audiovisual material (eg cameras, computers, microphones and the like); Partners fund the project.

\section{Key Activities}

What is needed to do in order to deliver the proposed solution?

Production and curation of educational content;

Development of own site to allocate the platform (UX, Dev);

Marketing engagement with

customers; Monitoring and

evaluation of student activities / Issuance of certificates.

\section{Key Resources}

What is a "must have" in order to run the business activities?

The main resources include: Environment and team for the elaboration of audiovisual educational content; Online platforms such as YouTube and its own site for content distribution; Team and marketing actions to reach customers, especially in social networks; Issuance of certificates and student progression assessments as a way to monetize the business.

Figure 3. Cost Structure components of the BMC.

Customer Segments

Who needs our solution?

Professionals in the industrial sector who seek professional and / or educational leverage, especially youngsters and adults, aged 20-35, who use the Internet to consume educational content in the form of videos

Another group of interest consists of learners not necessarily members of the industrial sector, who might be seeking information related to solving some personal problem, or aquiring new knowledge and/or technical skills.

\section{Channels}

How we deliver our solution to the customers?

The priority communication channel is the Internet itself, especially on platforms such as YouTube, which is the most accessed today for the consumption of video content.
Customer Relations

How do we talk to our customers about our solution?

The users will have ways inside the platform by which they can give feedbacks and suggestions, not only about the platform itself, but aiming content creation as well. Comment sections in social media is also a space worth monitoring to stablish communication with the customers.

Figure 4. Revenue Streams components of the BMC. 


\section{CONCLUSION}

As discussed in this article, the proposed microlearning-based platform aims to deliver quality educational content so that industry professionals, mostly young people and adults aged 20 to 35 , have access to a continuous formation focused on their urgent needs, identified in a research previously done by SENAI. One of these aspects raised by the research is of vital importance to the business, since it deals with how the services provided can be monetized. The survey identified that only a small portion of video consumers and online courses are willing to pay for the content consumed, suggesting that a freemium monetization approach would be more appropriate. In a freemium business model, the user would have access to content for free, and the revenue would be generated by issuing certificates and assessing student performance. Another important point to note is the participation of funding partners for the project, which in this case are the state-owned SENAI, and other partner companies, which are part of the industry. The main activities required for the delivery of the business are the production of the contents to be made available (from its pedagogical conception to its availability), dissemination of the content and the platform in digital media and social networks, and evaluation and issuance of certificates for students.

The relationship with the client will occur in an iterative way, allowing feedback on the available content and suggestion of new topics to be addressed, going against the profile of clients who are interested in customizable services.

In this way, we have a business model with potential to face the main difficulties faced by eLearning currently, considering the pains and needs of customers, and the economic scenario of the digital courses market for the coming years in Brazil. Although a beta version of the platform has already been developed, currently, the content to be provided is still being produced and being evaluated. The platform is still in its primary stages, so future studies will be needed to evaluate the aspects of this BMC, as the business develop. Then, it will be able to analyze the strengths and weaknesses of the model, though the successes and attention points raised by the iteration of the platform to its audience.

\section{REFERENCES}

[1] Baran, E. (2014). A Review of Research on Mobile Learning in Teacher Education. Journal of Educational Technology \& Society, pp. Volume 17: Number. 4 pp. 17-32.

[2] Newhouse, C. P. (2006). Supporting mobile education for pre-service teachers. Australasian Journal of Educational Technology.

[3] Shah, D. (18 de January de 2018). Fonte: Class Central: https://www.class-central.com/report/mooc-stats2017/

[4] COURSERA. Impact revealed: learner outcomes in open online courses. Disponível em: . Acesso em: 28 maio 2018.

[5] Attwell, C. \&. (2009). Appropriating technologies for contextual knowledge: Mobile personal learning environments. World Summit on Knowledge Society. Springer.

[6] Serviço Nacional de Aprendizagem Industrial SENAI. (2018). Retratos do consumo de vídeos on-line na área da indústria. Brasília.

[7] Zhang, X. a. (2011). Design for application of micro learning to informal training in enterprise. Artificial Intelligence, Management Science and Electronic Commerce (AIMSEC), 2nd International Conference on. IEEE.

[8] Bruck, P. A. (2012). "Mobile Learning with Micro-content: A Framework and Evaluation. Bled eConference.

[9] Baden-Fuller, C. a. (2013). Business models and technological innovation. Long range planning 46.6, pp. 419426.

[10] Chesbrough, H. a. (2002). The role of the business model in capturing value from innovation: evidence from Xerox Corporation's technology spin-off companies. Industrial and corporate change, pp. 529-555.

[11] Osterwalder, A. a. (2004). THE BUSINESS MODEL ONTOLOGY. LAUSANNE: UNIVERSITE DE LAUSANNE.

[12] Osterwalder, A. (2010). Business model canvas. Self published.

[13] Macedo, M. A. (2013). Bussines Model Canvas: a construção do modelo de negócio de uma empresa de móveis. X SEGeT-Simpósio de Excelência em Gestão e Tecnologia. 